\title{
MELLAN HUMMER OCH PÖLSA - KULINARISK TRANSITION I TORGNY LINDGRENS OCH ELLA NILSSONS MATEN
}

\author{
Krzysztof Bak \\ Stockholms universitet, Stockholm \\ Uniwersytet Jagielloński, Kraków \\ kr.bak@littvet.su.se
}

\begin{abstract}
The contribution investigates culinary transitions between Sweden and Europe in Torgny Lindgren's and Ella Nilsson's epistolary cookbook, Maten. Hunger och törst $i$ Västerbotten (2003) (Food: Hunger and Thirst in Västerbotten). With a theoretical starting point in discourseanalytic approaches to nationalistic ideology, primarily elaborated within cultural studies, the contribution examines uses of the binarity of Sweden/Europe in essentialist and deconstructive practices of the cookbook. The argument comprises three parts. In the first part, the cookbook's conception of Västerbottenian cuisine is scrutinized. It is argued that Lindgren's and Nilsson's construction of gastronomic Västerbottenianness brings into play a whole range of rhetorical strategies that are usually utilized to construct national cuisines. Västerbottenian cookery is: (a) codified as a normative canon, (b) connected to a specific place, to a historical tradition and to ritualized customs, (c) defined as a restitution project preserving regional heritage from entropy, and (d) organized according to certain culinary icons, each of which mythologically incarnates some part of the "soul" of the region. The second part discusses the position of Europe on the cookbook's gastronomic map. The concept of Europeanness in Maten is shown to be constructed as a cultural "Other" and - by analogy with other counter-images - (a) excluded from the field of genuine cookery, (b) smuggled into the cookbook's culinary discourse through devices of disguise and (c) manifest in "typical" Västerbottnian recipes its presence in "typical" Västerbottenian recipes by generating contradictions, semantic displacements and aporetic paradoxes. The final part examines the role of Sweden among the cookbook's gastronomic identities. Unlike traditional cookery books dedicated to Swedish national cuisine, Maten problematizes the relationship between centre and periphery, constructing Swedishness as a "double" identity: both the internalized "Self" and the oppressive "Other". Correspondingly, Lindgren and Nilsson have an ambiguous, partly ironic, attitude towards their own local patriotic cuisine project using the notion of "Saminess" to undermine Västerbottenian culinary logocentrism.
\end{abstract}

\section{Nyckelord}

Torgny Lindgren, Ella Nilsson, Västerbotten, svenskhet, Europa, nationalkökskonstruktion, det svenska köket, västerbottnisk matkultur, essentialisering, supplementering

En inte obetydlig del av den kulturella transitionen mellan Sverige och Europa sker på det kulinariska fältet. Den svenska matkulturen har alltid fått inspiration från kontinenten. Många av den svenska husmanskostens mest klassiska rätter har utländska rötter: kåldolmarna i

Tijdschrift voor Skandinavistiek 36(2), 2018/19 (co) EY

\footnotetext{
Except where otherwise indicated, the content of this article is licensed and distributed under the terms of the Creative Commons Attribution 3.0 License, which permits unrestricted use, distribution, and reproduction in any medium, provided the original work is properly cited.
} 
Turkiet, plättarna i Ryssland, sjömansbiffen i Frankrike (Wretman, 1981, 8; Jakobsson \& Wägner, 1963, 10f). Även om Sverige i denna gastronomiska utrikeshandel ständigt noterat ett betydande underskott, har det svenska köket också lyckats marknadsföra några av sina skapelser internationellt. När det fashionabla Hotell Hilton öppnade i Berlin 1960, firades invigningen med ett svenskt smörgåsbord (Sjöstrand \& Hentzel, 1967, 9). Genom sina restauranger och matbutiker exporterar IKEA traditionella svenska rätter till drygt 40 europeiska och utomeuropeiska länder.

Den svensk-europeiska mattransitionen speglas på ett intressant sätt i den svenska kokbokslitteraturen. I regel är kokböcker mycket informationsrika. Utöver de vanliga recepten kan de innehålla kulturhistoriska digressioner, personliga anekdoter, detaljerade kommentarer kring matprodukter och matlagningspraktiker. Hela den mångfaldiga textapparaten organiseras i kokbokslitteraturen av några ideologiskt laddade diskursivt-retoriska strategier, som har till uppgift att påverka läsarna och konsumenterna. Med särskild kraft kontrollerar de kokböckernas bild av den kulinariska transitionen, eftersom oppositionsparen vi/de, hemma/borta, det kända/det främmande, som bygger upp transitionsbilden, har en stark ideologisk potential och spelar en nyckelroll i de flesta ideologiska system (Metzger, 2005, 24, 33ff, 103).

Jag ska diskutera här hur den kulinariska transitionen mellan Sverige och Europa framställs i Maten. Hunger och törst $i$ Västerbotten (2003), en kokbok samförfattad av Torgny Lindgren (1938-2017) och Ella Nilsson (född 1945). Om Lindgrens starka matintresse vittnar titlarna på några av hans mest kända romaner: Hummelhonung (1995), Pölsan (2002), Norrlands akvavit (2007). Nilsson är en profilerad matskribent, TV-kock och lärare med bakgrund i Västerbotten. För sina gastronomiska insatser utnämndes hon våren 2016 till hedersdoktor vid Umeå universitet (Melander, 2016). Kokboken Maten är utformad som en brevdialog mellan de båda författarna. Genom sin fria, litterariserade karaktär är den ett tacksamt objekt för studiet av matideologiska konstruktioner.

Redan kokbokens titel - Maten. Hunger och törst $i$ Västerbotten - markerar att det inte är transitionen mellan Sverige och Europa som står i centrum för skribenternas intresse. Deras kulinariska fokus är den västerbottniska matkulturen. I sin avhandling I köttbullslandet. Konstruktionen av svenskt och utländskt på det kulinariska fältet visar ekonomihistorikern Johannes Metzger att det svenska nationalköket är ett relativt nytt, senmodernistiskt koncept. Det skapas i en rad inflytelserika kokböcker från 1960-talet och framåt, exempelvis Oskar Jakobssons och Ria Wägners Svenska landskapsrätter (1963) och Tore Wretmans Svensk husmanskost (1967), som alla arbetar med en rad avancerade diskursiva och retoriska strategier (Metzger, 2005, 328ff, 363ff). Samma strategier är verksamma i Maten. Men deras uppgift här är inte att konstruera det nationalsvenska utan det västerbottniska köket. Eftersom strategierna samtidigt på ett avgörande sätt styr kokbokens belysning av den svensk-europeiska transitionen, ska jag börja med att presentera dem.

En grundläggande roll för konsolideringen av nationalkökskonstruktionen spelar essentialiseringen. Det svenska köket framställs som ett slags metafysiskt vara, som utmärker sig genom några fixerbara identitetsgivande egenskaper (Burstedt, 2001, 63ff, 67; Metzger, 2005, 301ff, 385). I Maten säger sig Lindgren vilja fånga in "Den västerbottniska maten 'i sig'، (Lindgren \& Nilsson, 2003, 200). Adjektivet västerbottnisk används genomgående som ett särskiljande attribut. För Nilsson åsyftar det oftast något helt konkret, för Lindgren snarare en

Tijdschrift voor Skandinavistiek 36(2), 2018/19

Except where otherwise indicated, the content of this article is licensed and distributed under the terms of the Creative Commons Attribution 3.0 License, which permits unrestricted use, distribution, and reproduction in any medium, provided the original work is properly cited. 
tanke eller föreställning ("västerbottniska föreställningar om vad som är koscher"), men båda ger uttrycket en metafysisk dignitet. Ständigt återkommande i deras brev är essentialistiska formuleringar: "skiljande väsen", “äkta", "ren", "tillbörlig", "klassisk", “egen”, "speciell”, "fullständig", "självförverkligad", "en sort för sig", "i själva verket och innerst inne" (Lindgren \& Nilsson, 2003, 32f, 36, 46, 75, 83, 112, 129, 156, 191). En påfallande hög frekvens i kokboken uppvisar epitetet riktig: "riktig mat", "riktig pölsa", "riktigt frasigt kornbröd", "riktigt orangegult smör" (Lindgren \& Nilsson, 2003, 5, 46, 127, 156, 187) etc.

Ett viktigt steg i konstruktionen av nationalköket är att det essentialistiska kökskonceptet formaliseras, det vill säga omsätts i en mat- och receptkorpus som kodifieras, normeras och kanoniseras (Metzger, 2005, 311, 335; Ashley m.fl., 2004, 75). Även i Maten skrivs idén om det västerbottniska köket ut på ett antal konkreta rätter: palt, tunnbröd, gravad röding, hjortronsylt etc. De presenterade recepten regleras av normativa uttryck av modal karaktär: bör, måste, ska, får, fordras. Att avvika från regelverket klassificeras av Lindgren som "nihilism" (Lindgren \& Nilsson, 2003, 53). Utmärkande för nationalkökskonstruktionerna är att kanoniseringen hellre än pragmatiska aspekter - hälsa, nytta, ekonomi, lätthanterlighet åberopar mer klassiska gastronomiska värden: tillfredsställelse, fulländad smakupplevelse, njutning (Warde, 1997, 78f, 90ff; Metzger, 2005, 163ff). Nilsson och Lindgren uppmanar gång på gång sin läsare att bejaka fettet, glömma "alla varningar om tungmetaller" och hänge sig åt "ogrumlad" kulinarisk "lycka" (Lindgren \& Nilsson, 2003, 166, 168). Kokbokens tongivande värderingsuttryck är: god, ljuvlig, smakrik, utsökt, läcker.

Den essentialistiskt koncipierade, formellt konsoliderande nationalkökskonstruktionen stabiliseras genom diskursivt-retoriska strategier som ska ge konstruktionen ett intryck av naturlighet. Många av dessa praktiker är relaterade till spatialitet. Den samlade receptkorpusen får en äkthetsstatus genom att den knyts till en nation, ett territorium, en lokalbefolkning, ett rumsbundet kulturmönster (Bell \& Valentine, 1997, 167ff; Murcott, 1996, 64ff; Cook \& Crang, 1996, 137ff) etc. Maten inleds med en karta över Västerbottens län och refererar ständigt till landskapets realia. Som västerbottniska klassas de rätter som tillagas av västerbottniska produkter, sammanfattar västerbottnisk natur, utgör en bas för västerbottningarnas identitet: "vi västerbottningar [...] har våra rötter i sådana recept. Tack vare dem har vi blivit vad vi är" (Lindgren \& Nilsson, 2003, 51, 63f, 91). I den svenska nationalkökskonstruktionen har territorialiseringen och etnifieringen en regionaliserande tendens (Jakobsson \& Wägner, 1963, 11f). Lindgren och Nilsson följer det mönstret inte bara genom att fokusera ett bestämt landskaps matlagningskultur utan också genom att underkasta det västerbottniska köket självt en regionaliserande differentiering. Då Lindgren i en längre teoretisk utvikning hävdar att det inte finns någon västerbottnisk mat, tar han inte avstånd från kokbokens essentialistiska skrivsätt utan flyttar det metafysiska nyckelverbet finnas till en mer partikulär nivå. Det finns, menar han, "inte ett Västerbotten utan ett otal" på samma sätt som "var bygd" och "Vart sjösystem" har sin egen pölsa: "En lidmanpölsa från Missenträsk är alls inte detsamma som en enquistpölsa från Hjoggböle eller en lindgrenpölsa från Raggsjö” (Lindgren \& Nilsson, 2003, 156).

Många av nationalkökskonstruktionens naturaliserande strategier är kopplade till tiden och kontinuiteten (Ashley m.fl., 2004, 86ff; Warde, 1997, 61ff). Den svenska matkorpusen legitimieras genom att den förankras i historien, familjearvet, den gamla traditionen (Wretman,

Tijdschrift voor Skandinavistiek 36(2), 2018/19 (c) EY

Except where otherwise indicated, the content of this article is licensed and distributed under the terms of the Creative Commons Attribution 3.0 License, which permits unrestricted use, distribution, and reproduction in any medium, provided the original work is properly cited. 
1981, 8; Metzger, 2005, 329ff). Lindgren och Nilsson refererar ständigt till sitt landskaps, sina hembygders och sina släkters förflutna. Hellre än kokböckernas vanliga imperativformer använder de erinringens preteritum. Till skillnad från många postmoderna tänkare som åberopar begreppet familjelikhet för att underminera essentialistiska entiteter utnyttjar Lindgren sina släkt- och historiereferenser för att styrka Västerbottens kulinariska särart. Alla dem som i något led är släkt med honom räknar han automatiskt som västerbottningar, även om de bor utanför det geografiska Västerbottens gränser (Lindgren \& Nilsson, 2003, 158). På ett analogt sätt blir flera rätter med något diffus västerbottnisk tillhörighet - köttgryta med morötter och vitkål, saltad fårost eller enbärsdricka - inkorporerade i det västerbottniska köket genom att de ingår i den lindgrenska släktens matminnen (Lindgren \& Nilsson, 2003, 56, 91f, 183).

Nationalkökskonstruktionen aktualiserar inte bara dåtiden och nuet utan också framtiden. De tre tidsdimensionerna förenas till en narrativ struktur, som följer komedins typiska kurva ordning-oordning-ordning och låter de gamla mattraditionerna utmynna i en framtidsinriktad aktivism. Nationalköket framställs som ett resultat av ett förnyelsearbete, som gör slut på nutidens kulinariska förfall genom att återuppliva historiens glömda matkultur (Wretman, 1981, 16; Metzger, 2005, 275, 291f; Murcott, 1996, 67). I Maten får uttrycken gammaldags, ursprunglig, beprövad, allra första en genomgående positiv klang. Nuet däremot knyts till allehanda gastronomiska krissymptom: vi "lagar allt mindre mat", vi hänvisas till "en enda sorts smör", vi har omotiverade fördomar mot efterrätter, vi kan inte längre glädjas åt primörer (Lindgren \& Nilsson, 2003, 35, 46, 159, 194) etc. Genom sitt kulinariska engagemang vill skribenterna återupprätta den genuina västerbottniska matkulturen. Nilsson beskriver hur hon åker på föredragsturnéer, ordnar växtodlingskurser, informerar lokala älgjaktlag - allt för att ge nytt liv åt den gamla västerbottniska mattraditionen (Lindgren \& Nilsson, 2003, 48, 63).

Nationalkökskonstruktionens mataktivism realiseras först och främst genom ritualisering. Enligt en beprövad essentialistisk tankefigur beskrivs den nationella mattraditionen som en sorts absolutifierad hypostas och den nutida delaktigheten i ursprungets idealverklighet som en rituell upprepning av hypostasens heliga paradigm (Jakobsson \& Wägner, 1963, 12; Metzger, 2005, 321f; Murcott, 1996, 49). I Maten framställs Västerbottens historiska matkultur som en del av Guds skapelseordning och knyts till attribut som "himmelsk", "fulländad", "oskuldsfull”, "outgrundlig", "innesluten i sin egen gåta" (Lindgren \& Nilsson, 2003, 36, 73, 75f, 179). Inte minst av den anledningen tvivlar Lindgren på att några framsteg inom matlagningskonsten är möjliga. Han vill se det nutida västerbottniska ätandet som en "sakramental" akt, en nattvardsliknande repetition av det sakraliserade urmönstret (Lindgren \& Nilsson, 2003, 108, 136).

Nationalkökskonstruktionens olika diskursivt-retoriska praktiker organiseras runt ett antal "nationella kulinariska ikoner", symboltecken med en naturaliserad, "mytifierad" relation mellan det betecknande och det betecknade (Metzger, 2005, 260, 345; Niskanen, 2007, 117). Lindgrens och Nilssons västerbottniska kök konsolideras på ett motsvarande sätt kring några representativa nyckelrätter - pölsa, kornmjölsgröt, långfil, Svantekakun - som aktualiseras genom hela kokboken och förses med ett allegoriskt djup. Syltefläsket till exempel får på ett arketypiskt vis förkroppsliga västerbottningens inre längtan som om bildens signifiant- och signifiéled formade en nödvändig, organisk enhet (Lindgren \& Nilsson, 2003, 113ff).

Tijdschrift voor Skandinavistiek 36(2), 2018/19

Except where otherwise indicated, the content of this article is licensed and distributed under the terms of the Creative Commons Attribution 3.0 License, which permits unrestricted use, distribution, and reproduction in any medium, provided the original work is properly cited. 
Maten. Hunger och törst $i$ Västerbotten presenterar det västerbottniska köket som ett sammanhållet, naturaliserat kulinariskt väsen. Var i detta självcentrerande koncept finns det plats för matens Europa? Lindgrens och Nilssons kokbok artikulerar den matkulturella transitionen mellan Sverige och kontinenten huvudsakligen på tre sätt: negativt, positivt och djupstrukturellt. Med den tredje aspekten åsyftas matlagningsdiskursens inre, retoriskt-logiska organisation. De negativa uttrycksformerna har med själva den identitetsskapande mekanismen att göra. Konstruktionen av en särart kräver att det som inte tillhör särarten utesluts, görs till en motbild, definieras som det Andra (Billig, 1995, 61). Den rollen tilldelar den svenska nationalkökskonstruktionen och Maten i stor utsträckning det europeiska (jfr Bell \& Valentine, 1997, 167). Eftersom det svenska och det västerbottniska köket etableras med både rums- och tidsrelaterade strategier, får Europas negativbild såväl en spatial som en historisk dimension. Inom det rumsliga är negativiseringen direkt kopplad till exkluderande och kontrasterande praktiker. På samma sätt som Wretman högtidligt utesluter till exempel wienerschnitzel, rostbiff och parisare ur den "riktigt svenska" husmanskosten (Wretman, 1981, 44, 125), inleds Maten med ett citat ur en matsedel, tänkt som en illustration av icke-riktig mat: " $\AA$ ̊ngkokt sjötunga med hummer, tryffel och vitvinssås. Serveras med kronärtskocksbottnar." (Lindgren \& Nilsson, 2003, 5). Listan på det kulinariskt främmande kompletteras så småningom med andra rätter, de flesta med europeisk konnotation: rysk kaviar, smörrebröd, risotto, gåslever, färskpotatis från Cypern (Lindgren \& Nilsson, 2003, 9, 30, 52, 85, 130). I linje med bokens essentialistiska synsätt presenteras dessa maträtter som brott mot varats naturliga ordning. De genererar en hel rad excessrelaterade attribut - pervers, onaturlig, konstig, besynnerlig, yvig, absurd, surrealistisk - och knyts till den berömda karamazovska formeln för syndafall och kaos, "Om Gud inte existerar, då är allting tillåtet", som genast överförs till det västerbottniska kökets föreställningsvärld: "Om allting är tillåtet, då kan vi västerbottningar använda grahamsmjöl i kornmjölsgröten och blodplasma i blodkorven och bakpulver i tunnbrödet och fläsk i kalvsyltan och gädda i mörtbullarna" (Lindgren \& Nilsson, 2003, 52f, 108).

På det historiska planet får det negativt laddade Europa en strategisk roll i kökskonstruktionens berättelse. Narrationen om nutidens kulinariska förfall använder olika hotoch fiendebilder. Den viktigaste är moderniteten, som i regel framställs som något universellt, kosmopolitiskt, europeiskt (Metzger, 2005, 289, 298; Burstedt, 2001, 77). I Maten deklarerar Lindgren att han avskyr "moderniteten i de flesta former" och berättar om ett besök i en butik för köksredskap i Paris, där han inte kunde hitta "ett gammaldags rivjärn av plåt", däremot en motordriven vitlökspress, en maskin för att krama ut buljong ur ankor och en rad andra tekniska nymodigheter (Lindgren \& Nilsson, 2003, 51f). Med samma motvilja beskriver han de "fabriksgjorda djupfrysta maträtter" han serverades vid en av boulevarderna (Lindgren \& Nilsson, 2003, 53). Pillermat, frysta halvfabrikat, monstruösa matlagningsmaskiner ingår i nationalkökskonstruktionens vanliga toposförråd med uppgift att exemplifiera modernitetens förödande verkan (Wretman, 1981, 9ff, 126; Algotson \& Englund, 1983, 9).

I den mån nationalkökskonstruktionen refererar till Europa i positiva sammanhang underkastas det europeiska en supplementering (Metzger, 2005, 305, 312). En av de soppkreationer Wretman lanserar i Svensk husmanskost är sandhamnssoppa, som, försäkrar han, "ortsbefolkningen i Stockholms skärgård mycket väl kan ha lagat och lagar". Att denna "hemortsrätt" kräver olivolja, timjan, basilika, rosmarin och citron lämnas utan förklaring

Tijdschrift voor Skandinavistiek 36(2), 2018/19 ((c)) EY

Except where otherwise indicated, the content of this article is licensed and distributed under the terms of the Creative Commons Attribution 3.0 License, which permits unrestricted use, distribution, and reproduction in any medium, provided the original work is properly cited. 
(Wretman, 1981, 37, 52f). Lindgrens och Nilssons kokbok utnyttjar - utan att skylta med det en lång rad råvaror som genom sina blotta namn aktualiserar Europa: parmaskinka, brysselkål, worcestershiresås, pilsner, Myrtenpfeffer, medelhavssalt, madeira, crème fraiche (Lindgren \& Nilsson, 2003, 30, 34, 65, 87, 110, 116, 127). Lika europeiska är stora delar av Lindgrens och Nilssons kulinariska fackvokabulär (gourmet, omelett), deras matlagningspraktiker (bräsering, blanchering) och deras matkulturella referenser: nätting kokad i gräddblandad mjölk associerar Lindgren med Johannes Brahms musik, barndomens och ynglingaårens näringsrika rätter med matskildringar i Thomas Manns romaner, det "västerbottniska ätandet" i sig med "van Gogs målning Potatisätarna" (Lindgren \& Nilsson, 2003, 55, 136, 169).

På det djupstrukturella planet märks Europa i nationalköksprojektet genom en diskursivtretorisk oordning. Ett vanligt pris för logocentriska konstruktionspraktiker är att det marginaliserade ledet destabiliserar konceptets inre organisation (Bell \& Valentine, 1997, 169). I nationalkökskonstruktionen skapas den sortens problem inte minst genom att det essentialistiskt tänkta nationalköket byggs upp av rent retoriska grepp, som innehållsligt är helt transparenta och kan användas till vad som helst (Warde, 1997, 46ff; Metzger, 2005, 36ff, 160ff, 244). Av den kokbokslitteratur som publicerats i Sverige under de senaste decennierna utgör de svenskorienterade kokböckerna bara en bråkdel. En kvantitativt långt starkare grupp är kokböcker - både verk av svenska matexperter och översättningar - ägnade åt andra europeiska matkulturer (Blomqvist, 1980, 224ff, 236ff; Metzger, 2005, 70, 303). Som flera kulturhistoriker visat växer båda kategorierna fram ur samma senmoderna längtan bort från modernismens kosmopolitiskt-industriella tänkande och tillbaka till det urgamla, agrara, naturliga (Harvey, 1989, 302f; Root, 1996, 78ff; Burstedt, 2001, 66f; Metzger, 2005, 214ff). I de europeiskt orienterade kokböckerna kanaliseras detta autenticitetssökande genom samma retoriska praxis som i exempelvis Svensk husmanskost med den enda skillnaden att det nu är det svenska som får spela det Andra och beskylls för att vara bristfälligt, smaklöst, artificiellt. Talande nog aktualiserades den typen av sverigekritiska strategier särskilt starkt under den period då det svenska köket etablerades som koncept (Metzger, 2005, 126ff, 135ff; Halling, 1952, 9, 83, 116; Pavia, 1961, 3ff). Kort sagt: nationalköksprojektets konstruktionsstrategier undermineras genom att de dialektiskt rymmer sina egna motbilder. I kokboken Maten antar denna retoriska labilitet mycket konkreta uttrycksformer. Lindgren presenterar ett centraleuropeiskt recept på fylld våm och laddar det med samma sorts positiva genuinitetstroper som han annars använder för att hävda det västerbottniska mot det europeiska (Lindgren \& Nilsson, 2003, 33f). De lokalpatriotiskt koncipierade figurerna visar sig kunna knytas till vilken kulinarisk plats som helst. Lindgren förklarar att han fătt våmreceptet från "ett par välfödda makar från Mödling" som han träffat på en Bierstube i Wien. I gengäld skänkte han dem, berättar han, sitt "mycket anspråkslösa recept på syltefläsk från Västerbotten” (Lindgren \& Nilsson, 2003, 34). De båda recepten fungerade som utbytbara storheter - både i bokstavlig och diskursivt-retorisk mening.

En vanlig diskursorganisatorisk följd av logocentrismen är aporetiska motsägelser, paradoxer, lakuner, asymmetrier. Kokboken Svenska regionalrätter försäkrar att Sverige kan "mäta sig med vilket annat ostproducerande land som helst" och uppställer därmed oavsiktligt de icke-svenska ostarna som norm (Jakobsson \& Wägner, 1963, 13). Wretman vill visserligen renodla det inhemska men har "en utländsk gäst" som sin ständiga referenspunkt (Wretman,

Tijdschrift voor Skandinavistiek 36(2), 2018/19 ((c) EY

Except where otherwise indicated, the content of this article is licensed and distributed under the terms of the Creative Commons Attribution 3.0 License, which permits unrestricted use, distribution, and reproduction in any medium, provided the original work is properly cited. 
1981, 14). I Maten hyllar Lindgren kryddat ister genom att likställa det med tyskarnas "Schmalz" (Lindgren \& Nilsson, 2003, 57). Nilsson vill slå vakt om det västerbottniska för att kunna "marknadsföra det till turisterna" (Lindgren \& Nilsson, 2003, 164). Hon hävdar visserligen att "risotton kan slänga sig i väggen", men namnet på den västerbottniska alternativrätt hon lanserar - "Kornotto" - bekräftar den italienska risottons originalstatus (Lindgren \& Nilsson, 2003, 30). Den typen av Europabejakande paradoxer genomsyrar konstruktionen av det västerbottniska köket i Maten.

Så långt har Lindgrens och Nilssons syn på transitionen mellan det egna och det främmande följt nationalkökskonstruktionens grundmönster. Men det finns åtminstone två remarkabla skillnader mellan Maten och den svenska nationalkökskonstruktionen. Nationalkokböckerna intar överhetens harmoniserande observationspunkt och problematiserar inte relationen mellan centralmakten och provinserna (Metzger, 2005, 330; Ashley m.fl., 2004, 87f). Lindgren och Nilsson däremot ger förhållandet mellan Västerbotten och Stockholm en ambivalent belysning. I protest mot huvudstadens hegemoni behandlar de den centralsvenska matkulturen på samma villkor som det kontinentala Europa: som det negerade Andra. Uttrycket sörlänning betyder i Lindgrens språkbruk såväl syd- och mellansvensk som kontinentaleuropé (Lindgren \& Nilsson, 2003, 9, 50, 117, 154f, 201). Å andra sidan visar både Nilsson, mångårig VD för Svensk Köttinformation, och Lindgren, ledamot i Svenska Akademien, samhörighet med hela riket (Lindgren \& Nilsson, 2003, 69, 76, 79). Många av kokbokens kontradiktioner låter sig återföras just på den här dubbelheten inför det rikssvenska. Falukorv exempelvis räknas i Maten som både en främmande lyxvara och en del av det rustikt västerbottniska (Lindgren \& Nilsson, 2003, 56, 114f, 120). Kritiken mot den rikssvenska kolonialismen minskar inte västerbottningarnas stolthet över att vara kungliga hovleverantörer och bidra till Nobelmiddagsmenyer (Lindgren \& Nilsson, 2003, 93, 132).

Den andra markanta skillnaden mellan nationalkokböckerna och Maten. Hunger och törst $i$ Västerbotten gäller tilltron till de logocentriska mekanismerna. Varken Svensk husmanskost eller Svenska landskapsrätter ifrågasätter sin essentialistiska nationalkökskonstruktion. I Maten däremot blir det västerbottniska köket ständigt underkastat en dekonstruerande prövning. Många av kokbokens meningsstörande mekanismer uppstår som ett resultat av ett medvetet estetiskt spel med de kulinariska betydelserna. En sådan destabiliserande effekt har inte minst den epistolärt-dialogiska formen. De båda brevskrivarna divergerar i sin syn på den kulinariska utvecklingen, tekniken, den västerbottniska renlärigheten. Lindgren markerar tydligt sitt bifall de gånger han solidariserar sig med Nilssons uppfattning: "Kära Ella, jo Du har säkert rätt" (Lindgren \& Nilsson, 2003, 9). Men lika starkt signalerar han sina reservationer: "Nej men Ella, Du måste ha missförstått mig" (Lindgren \& Nilsson, 2003, 168). Genom den sortens intersubjektiva inslag laddas de diskuterade gastronomiska ämnena med en ambivalensskapande polyfoni (Lindgren \& Nilsson, 2003, 51, 108). Till kokbokens konnotativa öppenhet bidrar också Lindgrens ironiska skrivsätt, som till en del övertas av hans medskribent. Wretman ställer entydigt sina ironier i den logocentriska kökskonstruktionens tjänst (Wretman, 1981, 10ff). Lindgrens ironifigurer däremot är alltid tvåeggade. Redan genom bokens kontrapunktiskt-ironiska titel markerar han en subversiv attityd till sitt kulinariska projekt. Samma anti-logocentriska funktion fyller hans groteska varning att ett alltför glupskt sysslande

Tijdschrift voor Skandinavistiek 36(2), 2018/19 (co) EY

Except where otherwise indicated, the content of this article is licensed and distributed under the terms of the Creative Commons Attribution 3.0 License, which permits unrestricted use, distribution, and reproduction in any medium, provided the original work is properly cited. 
med "'det i-sig-liga' eller 'det varandes i-sig-väsendes-varande"“ lätt kan leda till övervikt (Lindgren \& Nilsson, 2003, 200). En icke oväsentlig roll i kokbokens självdekonstruerande praxis spelar bilden av den västerbottniska matkulturens nordliga granne: det samiska. På samma sätt som det rikssvenska laddas även det samiska i Maten med semantisk dubbelhet: det framställs som både det egna och det främmande. Å ena sidan betecknas samerna genomgående som "de" och knyts till egna, exotiskt klingande rätter (gaahko, juobmo, gompa). Lappland och Västerbotten skiljs åt som två autonoma landskap: "Det är inte Västerbotten, sade jag. Det är Lappland" (Lindgren \& Nilsson, 2003, 154, 162ff). ̊̊ andra sidan framhävs breda, inte minst kulinariska beröringsytor mellan det västerbottniska och det samiska. Lindgren konstaterar att en dryck gjord på fjällväxter och torkade renöron - "receptet lär vara samiskt" - "smakar Västerbotten" (Lindgren \& Nilsson, 2003, 203). Men medan Sveriges två roller får en positiv respektive negativ konnotation, närsläktingens respektive kolonisatörens, genererar det samiska enbart positiva uttryck - exklusivast, godast, delikatess, skatt - och utnyttjas för en kritik av den västerbottniska kökskonstruktionen. Lindgren och Nilsson medger att västerbottningarna, hyllade för sin kulinariska uppfinningsrikedom, "lärde sig åtskilliga knep av samerna. Salta, soltorka, kallröka under takåsarna" (Lindgren \& Nilsson, 2003, 22, 149, 155f, 164). Liksom rikssveriges provinsställning görs till ett levande belägg på kontinentens smaknormerande envälde och liksom Västerbottens utkantsposition på ett analogt vis tolkas som en indikator på rikssveriges matkulturella expansionism, får de av de västerbottniska nybyggarna undanknuffade samerna i sin tur demaskera Västerbottens kulinariska självgodhet.

\section{Bibliografi}

Algotson, S. \& G. Englund (1983). Den svenska maten. Husmanskost och kalasmat från jordbrukets provkök. Stockholm: LTs förlag.

Ashley, B. m.fl. (2004). Food and cultural studies. London: Routledge.

Bell, D. \& G. Valentine (1997). Consuming geographies. We are where we eat. London: Routledge.

Billig, M. (1995). Banal nationalism. London: Sage.

Blomqvist, H. (1980). Mat och dryck i Sverige. En litteraturöversikt. Stockholm: LTs förlag.

Burstedt, A. (2001). Platsen är serverad! I K. Hansen \& K. Salomonsson (red.), Fönster mot Europa. Platser och identiteter (61-86). Lund: Studentlitteratur.

Cook, I. \& P. Crang (1996). The world on a plate. Culinary culture, displacement and geographical knowledges. Journal of Material Culture 1:2, 131-153.

Halling, A. (1952). Resa i franskt kök. Stockholm: Wahlström \& Widstrand.

Harvey, D. (1989). The condition of postmodernity. An enquiry into the origins of cultural change. Oxford: Blackwell.

Jakobsson, O. \& R. Wägner (1963). Svenska landskapsrätter. Stockholm: Generalstabens Litografiska Anstalts Förlag \& Svenska Turistföreningen.

Lindgren, T. \& E. Nilsson (2003). Maten. Hunger och törst i Västerbotten. Stockholm: Norstedts.

Melander, P. (2016), Ella Nilsson utsedd till hedersdoktor. Hämtat från http://www.humfak.umu.se/nyhet//.cid269399 13.2.2017.

Tijdschrift voor Skandinavistiek 36(2), 2018/19

Except where otherwise indicated, the content of this article is licensed and distributed under the terms of the Creative Commons Attribution 3.0 License, which permits unrestricted use, distribution, and reproduction in any medium, provided the original work is properly cited. 
Metzger, J. (2005). I köttbullslandet. Konstruktionen av svenskt och utländskt på det kulinariska fältet. Stockholm: Acta Universitatis Stockholmiensis.

Murcott, A. (1996). Food as an expression of identity. I S. Gustavsson \& L. Lewin (red.), The future of the national state. Essays on cultural pluralism and political integration (49-77). London: Routledge.

Niskanen, K. (2007). Det svenska nationella köket - en social och kulturell konstruktion. Historisk Tidskrift, 127:1, 112-118.

Pavia, A.-B. (1961). Italienska recept. Stockholm: Rabén \& Sjögren.

Root, D. (1996). Cannibal culture. Art, appropriation, and the commodification of difference. Boulder: Westview.

Sjöstrand, J. \& R. Hentzel (1967). Smörgåsbord och småvarmt. Stockholm: Natur och Kultur.

Warde, A. (1997). Consumption, food, and taste. Culinary antinomies and commodity culture. London: Sage.

Wretman, T. (1981, 1:a uppl. 1967). Svensk husmanskost. En samling gamla svenska recept anpassade till vår tids matlagningsmetoder. Stockholm: MånPocket.

\section{Biografisk notis}

Krzysztof Bak, dr hab., docent och universitetslektor, verksam vid Institutionen för kultur och estetik, Stockholms universitet, och vid Zakład Filologii Szwedzkiej, Uniwersytet Jagielloński, Kraków. Har publicerat monografier om P.D.A. Atterboms Lycksalighetens $\ddot{o}$ och B. Trotzigs Dykungens dotter samt artiklar om svenska författare som Edith Södergran, Astrid Lindgren, Thorsten Jonsson, Sara Lidman, Ulf Eriksson, Magnus Dahlström m.fl. Är särskilt intresserad av litteraturteoretiska problem som intertextualitet, litterär hermeneutik och narratologi.

Tijdschrift voor Skandinavistiek 36(2), 2018/19 (cc) Er

Except where otherwise indicated, the content of this article is licensed and distributed under the terms of the Creative Commons Attribution 3.0 License, which permits unrestricted use, distribution, and reproduction in any medium, provided the original work is properly cited. 